\title{
A whiff of mystery on Mars
}

\section{The surprising discovery of methane in Mars's atmosphere could be a sign of life there. Researchers are now working out how to find its source, reports Katharine Sanderson.}

or the past decade, NASA's mantra for exploring Mars has been to 'follow the water'. The agency based its aqueous obsession on the idea that finding evidence of past or present water would yield clues to whether life once graced the planet - or still exists there. Now, some scientists are chanting a new slogan: 'follow the methane'.

This small hydrocarbon is tantalizing because much of the methane in Earth's atmosphere is produced by microbes, within soils and inside the guts of cows and other mammals, including humans. So the fact that methane has been discovered on Mars could signal the presence of life somewhere on the red planet. Or not. Methane can also form through geological processes.

In either case, the methane findings signal that unknown processes are happening. "Methane is one molecule that really tells us that Mars is a coupled system of the interior, the surface and the atmosphere," says Sushil Atreya, director of the Planetary Science Laboratory at the University of Michigan in Ann Arbor.

In November, fans of Martian methane gathered in Frascati, Italy, to puzzle over the new data. They hope to pinpoint where the methane is coming from and why it gets scrubbed from the atmosphere so quickly. Solutions to these conundrums will require better data, so researchers are working out how to sniff out the gas in future missions to Mars.

The excitement over methane started to build in 2003 and 2004, when three groups ${ }^{1-3}$ spotted methane in the atmosphere of Mars using spectroscopic measurements from telescopes on Earth and data from the European Space Agency's Mars Express spacecraft. The amounts of methane detected by the teams differed, but the planetary average was estimated to be about 10 parts per billion by volume ${ }^{3}$, an extremely low level. And the amount changed over time - suggesting that the gas is still being released, even though it might have been produced at some point in the past.

In January 2009, the leader of one of the teams, Michael Mumma from NASA's Goddard Space Flight Center in Greenbelt, Maryland, published a paper ${ }^{4}$ that reanalysed his 2003 and 2006 observations from the Keck telescope and the Infrared Telescope Facility in Hawaii. Mumma's team showed that three neighbouring areas on Mars, Nili Fossae, Terra Sabae and Syrtis Major, were 'hot spots' of methane production during 2003. But by 2006, methane levels had dropped at those sites, signalling that some active process was venting the gas.

The quick drop also suggests that something is rapidly destroying the methane. "For us atmospheric chemists, it is still very difficult to understand how methane can vary so rapidly in time and space," says Franck Lefèvre at the Laboratory of Atmospheres, Environments and Space Observations in Paris.

Lefèvre calculated that the atmospheric lifetime of methane is less than 200 days $^{5}$ hundreds of times shorter than prevailing

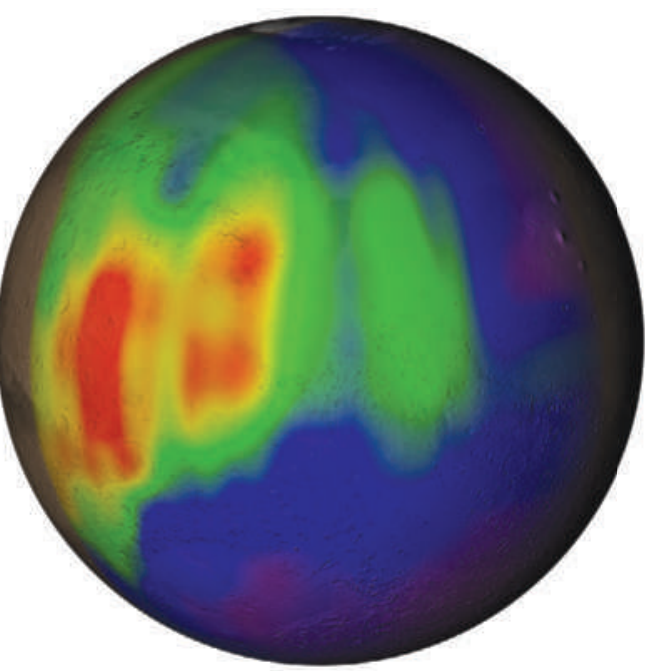

Plumes of methane (red is high concentration, purple is low) were seen on Mars in 2003.

models of Mars's atmosphere predict. "If the measurements are correct, this means that we are missing something really important," says Lefèvre.

Raina Gough, a PhD student at the University of Colorado at Boulder, tried to fill that gap by testing how methane reacts with samples made up to resemble Martian soil. But none of the soil samples removed methane that quickly, she reported at the meeting.

Gough's results were among the most important presented there because they "tend to rule out what was thought to be the most likely explanation for the observed methane variations on Mars", Lefèvre says. "The mystery deepens."

Where the gas is going is not the only problem. "The big question really is what is producing the methane," says Atreya. Is it biological or geological, past or present?

Although conditions on the surface of Mars are extremely harsh, there may be spots below the surface where microbes could survive. In research in the high Arctic, microbiologist Lyle Whyte from McGill University in Montreal, Canada, has found methane-making microbes within extremely salty pools in the permafrost, the permanently frozen ground. Martian microbes, if they exist, could be making methane in conditions somewhat like this on Mars, he suggests.

Alternatively, the methane could be forming geologically as a by-product of a process called serpentinization, which happens on Earth when water reacts with olivine, a mineral that is present on Mars ${ }^{6}$.

Another debate that dominated the meeting revolved around the location of the methane sources. Vittorio Formisano and Anna Geminale from the Institute of Physics of Interplanetary Space in Rome have tried to pinpoint the seasonal bursts using the Planetary Fourier Spectrometer on the Mars Express spacecraft. Their findings suggest that trace amounts of methane are released from the northern polar cap when its surface melts during summer.

The Keck data argue otherwise, say Mumma and Geronimo Villanueva, also at Goddard. The water released from the north pole in summer does not contain any methane, they say. And although the pair found their first three methane hot spots in the northern hemisphere, they have also identified methane releases in the southern part of the planet during that hemisphere's spring. The team is now using the Keck telescope to pinpoint the sources to regions as small as 80 kilometres, from the original best resolution of 500 kilometres.

The reason for the different conclusions could stem from the methods the two teams used. The Mars Express data are averaged over many thousands of spectra, and over time, whereas the Keck maps are snapshots. The disagreement and the failure of atmospheric models to explain the methane measurements has meant that some researchers remain sceptical about the interpretation of the data. Todd Clancy at the Space Science Institute in Boulder is particularly troubled by the fluctuations in time and space that Mumma reports. "These variations 


\section{MISSIONS TO MARS ... AND ITS METHANE}

Discoveries of methane on Mars have prompted efforts to investigate the source of the gas. Space agencies have several planned missions, depicted here, that could provide information about methane, and researchers are developing additional proposals that could fly at some future date.

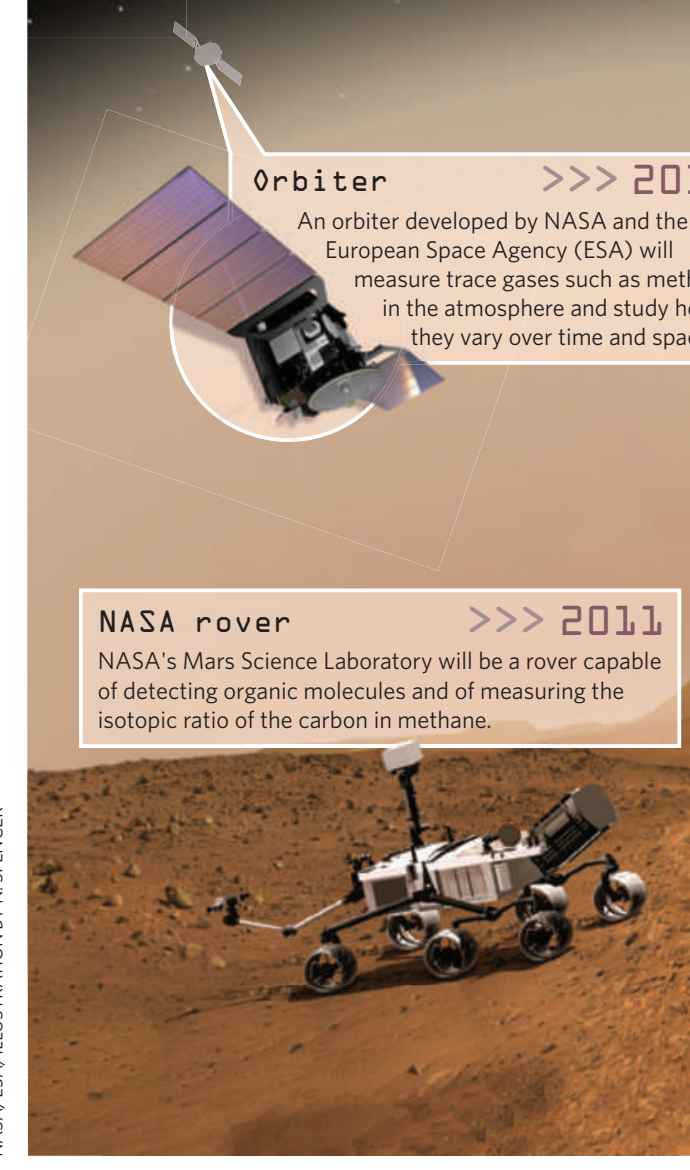

are unphysical for any plausible photochemical processes active in the Mars atmosphere," says Clancy. Yet, he says, if the observations are right, "the existence of such methane in the current Mars atmosphere would be profound on so many levels as to constitute the highest priority for planetary mission studies".

With so many questions swirling around the issue of methane, researchers agree that only new missions to Mars will provide the answers (see graphic).

\section{Chasing a gas}

First up is NASA's Mars Science Laboratory, which is due to launch next year. This car-sized rover will carry a tunable laser spectrometer, which should be able to answer one of the burning questions about Martian methane: what is the isotopic make-up of the carbon? If the carbon is mostly the lightest stable isotope, carbon-12, this could hint at a biological origin.

In 2016, NASA and the European Space Agency are scheduled to send an orbiter to monitor trace gases. At the Frascati meeting, Richard Zurek, chief scientist for the Mars programme at NASA's Jet Propulsion Laboratory in Pasadena, California, described this newly selected mission, which would be the first to look expressly for methane and other trace gases in the Martian atmosphere. The mis- sion has methane enthusiasts salivating, and the call for instrument proposals has just gone out. For researchers with questions about the methane data, the 2016 mission should provide some firm answers. "It will measure the level of methane on Mars unambiguously and determine whether it really is seasonally and latitudinally variable," says David Catling from the University of Washington in Seattle.

But some researchers are looking beyond the planned missions and are drawing up proposals for other ways to study the gas. Mumma would like to find active vents and watch them closely to see how methane releases change over time. He has proposed the Mars Organics Observer, which would sit at Mars's first Lagrange point, a special orbit around the Sun that is locked to the movement of Mars by the gravity of both bodies. The telescope could monitor the red planet every day and locate methane bursts with a resolution of 10 kilometres.

Others have placed drilling operations at the top of their wish lists. "Most astrobiologists believe that the best hope for detecting microbial life will be in the subsurface," says Whyte.

Researchers are also dreaming up other schemes for tracing methane sources. Atreya, and Paul Mahaffy from Goddard, propose using a balloon to measure gases in the Martian atmosphere. Joel Levine, at Nasa Lang- ley Research Center in Hampton, Virginia, is developing a Mars plane that could soar over the planet and monitor methane releases from the surface.

But those not directly involved in methane research caution about leaping on to the gas bandwagon. "We know that methane can be made by processes that have nothing to do with biology," says David Stevenson from the California Institute of Technology in Pasadena. Water should remain the research priority, he says.

Lefèvre, however, says he is happy that mission planners are hearing the wishes of methane enthusiasts. "Atmospheric chemistry has rarely been the trendiest topic in Mars science, but this has completely changed since the discovery of methane," he says. "We are now designing space missions entirely devoted to the detection of trace species, which was impossible to imagine a few years ago."

Katharine Sanderson is a reporter for Nature in London.

1. Mumma, M. J. et al. Bull. Am. Astron. Soc. 35, 937 (2003).

2. Krasnopolsky, V. A., Maillard, J. P. \& Owen, T. C. Icarus 172 537-547 (2004)

3. Formisano, V., Atreya, S., Encrenaz, T., Ignatiev, N. \& Giuranna, M. Science 306, 1758-1761 (2004)

4. Mumma, M. J. et al. Science 323, 1041-1045 (2009).

5. Lefèvre, F. \& Forget, F. Nature 460, 720-723 (2009)

6. Oze, C. \& Sharma, M. Geophys. Res. Lett. 32, L10203 (2005). 